\title{
Elastic wave velocities and Raman shift of MORB glass at high pressures -Comment
}

\author{
Masami KANZAKI \\ Institute for Study of the Earth's Interior, Okayama University, Misasa, Tottori 682-0193, Japan
}

In a recent issue, Kono et al. (2008) reported that they observed broad Raman bands at 1350 and $1600 \mathrm{~cm}^{-1}$ in their MORB glass sintered at approxiametly $17 \mathrm{GPa}$ and 900 ${ }^{\circ} \mathrm{C}$. They claimed that these bands are attributed to firstorder Raman scattering from the glass structure, most likely related to the high coordination silicon. They also measured the Raman shift of the $1600 \mathrm{~cm}^{-1}$ band up to 20 $\mathrm{GPa}$ and correlated its apparent nonlinear behavior with elastic wave velocities measured independently under pressure. However, as is explained below, these Raman bands are not due to vibrations of the MORB glass structure but merely due to carbon contamination.

The vibrational (Raman and infrared) properties of minerals and glasses/melts, including those under pressure, are now firmly established (Williams, 1995; McMillan et al., 1996; Gillet et al., 1998; Mysen and Richet, 2005). Assignment of vibrational bands of glasses or minerals should be based on this solid foundation. First-order Raman and infrared bands of $\mathrm{T}-\mathrm{O}$ stretching vibrations for tetrahedral cations (where $\mathrm{T}=\mathrm{Si}, \mathrm{Al}$ ), lie in the range between 700 and $1200 \mathrm{~cm}^{-1}$ (e.g., Williams, 1995). With increasing coordination number, each $\mathrm{T}-\mathrm{O}$ bond becomes weaker, resulting in even lower stretching vibrational frequencies. For octahedral $\mathrm{Si}$, the $\mathrm{Si}-\mathrm{O}$ stretching vibrations generally appear at $600-900 \mathrm{~cm}^{-1}$ (Williams, 1995; Gillet et al., 1998). Frequencies for bending and other vibrational modes appear in lower wavenumber regions than those for stretching vibrations. Therefore, the broad Raman bands at 1350 and $1600 \mathrm{~cm}^{-1}$ observed by Kono et al. (2008) cannot be explained by vibrational modes of the MORB glass. Although the first overtones of the abovementioned first-order modes may appear in this region, such a possibility is unlikely because there are no corresponding first-order bands in their Raman spectrum.

Therefore, the broad bands at 1350 and $1600 \mathrm{~cm}^{-1}$ probably originate from a contaminant introduced in the

doi:10.2465/jmps.080514

M. Kanzaki, mkanzaki@misasa.okayama-u.ac.jp Corresponding author glass during the sintering process. A possible candidate responsible for the $1600 \mathrm{~cm}^{-1}$ band is water. The frequency of the $\mathrm{H}-\mathrm{O}-\mathrm{H}$ bending mode of molecular water in hydrous glasses is known to appear at around $1600 \mathrm{~cm}^{-1}$ (Mysen and Richet, 2005). However, the intensity of the $1600 \mathrm{~cm}^{-1}$ band observed by Kono et al. (2008) is higher than those of other bands. This implies that the glass contains more than few weight percentages of water (Mysen and Richet, 2005). Although details on how the glass was sintered are not provided, it is unlikely to have such significant water contamination. This possibility can easily be verified by measuring the Raman spectrum of the $\mathrm{OH}$ stretching region (2000-4000 $\left.\mathrm{cm}^{-1}\right)$.

Then, what are the origins of these two bands? In fact, it is well known that such bands are a result of carbon contamination (McMillan et al., 1991). Raman spectra of poorly crystallized graphite are known to contain broad bands at 1350 and $1600 \mathrm{~cm}^{-1}$, and the intensity ratio of these two bands has commonly been used to characterize carbon material (McMillan et al., 1996). Carbon coating commonly used for SEM and EPMA analyses also yields similar Raman spectra. The spectrum of the sintered MORB glass reported by Kono et al. (2008) is very similar to those of poorly crystallized graphites. By micro-Raman spectroscopy, carbon contaminations have also been previously observed in quenched run products of multi-anvil high-pressure experiments (Hemley et al., 1986; McMillan et al., 1991). Possible carbon sources are the graphite heater, an organic contaminant, glue, and $\mathrm{CO}_{2}$ adsorbed on the surface of the sample and on parts of the cell before high-pressure treatment. These carbon-containing materials would transform into poorly crystallized graphite during high-pressure and high-temperature processing. If careful precautions are not taken, such contamination would be inevitable. It should be noted that this poorly crystalline graphite has been found even in the $\mathrm{P}-\mathrm{T}$ stability field of diamond (e.g., McMillan et al., 1991).

In order to further confirm the carbon contamination hypothesis, the pressure dependence of the $1600 \mathrm{~cm}^{-1}$ 
band observed by Kono et al. (2008) is compared with results of previous in-situ Raman studies of graphite. Hanfland et al. (1989) and Aleksandrov et al. (1992) measured Raman spectra of graphite and graphite-related materials under pressure. They showed that a band at around 1580 $\mathrm{cm}^{-1}$ at ambient pressure shifted to $1620-1650 \mathrm{~cm}^{-1}$ at 10 $\mathrm{GPa}$. This behavior is very similar to that observed by Kono et al. (2008).

In summary, it is clear that the broad bands at 1350 and $1600 \mathrm{~cm}^{-1}$ observed by Kono et al. (2008) are most probably due to a poorly crystallized graphite contaminant in their sintered MORB glass. Therefore, until further supporting evidences can be obtained, their claims regarding the structural change of the MORB glass under pressure should be dismissed.

\section{ACKNOWLEDGMENTS}

The author thanks Dr. Xianyu Xue for assistance with improvement of the manuscript.

\section{REFERENCES}

Aleksandrov, I.V., Goncharov, A.F., Yakovenko, E.V. and Stishov, S.M. (1992) High pressure study of diamond, graphite and related materials. In High-Pressure Research: Application to Earth and Planetary Sciences (Syono, Y. and Manghnani, M.H. Eds.). pp. 530, Terra Scientific Publishing Company, Tokyo/American Geophysical Union, Washington, DC, 409416.
Gillet, P., Hemley, R.J. and McMillan, P.F. (1998) Vibrational properties at high pressures and temperatures. In UltrahighPressure Mineralogy, Reviews of Mineralogy Vol. 37 (Hemley, R.J. Ed.). pp. 671, Mineralogical Society of America, Washington, DC, 525-590.

Hanfland, M., Beister, H. and Syassen, K (1989) Graphite under pressure: Equation of state and first-order Raman modes, Physical Review B, 39, 12598-12603.

Hemley, R.J., Mao, H-K. and Chao, E.C.T. (1986) Raman spectrum of natural and synthetic stishovite, Physics and Chemistry of Minerals, 13, 285-290.

Kono, Y., Ohfuji, H., Higo, Y., Yamada, A., Inoue, T., Irifune, T. and Funakoshi, K. (2008) Elastic wave velocities and Raman shift of MROB glass at high pressures, Journal of Mineralogical and Petrological Sciences, 103, 126-130.

McMillan, P.F., Akaogi, M., Sato, R.K., Poe, B. and Foley, J. (1991) Hydroxyl groups in $\beta-\mathrm{Mg}_{2} \mathrm{SiO}_{4}$, American Mineralogist, 76, 354-360.

McMillan, P.F., Dubessy, J. and Hemley, R. (1996) Applications in Earth, Planetary and Environmental Sciences. In Raman Microscopy Developments and Applications (Turrell, G. and Corset, J. Eds.). pp. 463, Academic Press, London, 289-365.

Mysen, B.O. and Richet, P. (2005) Silicate Glasses and Melts Properties and Structure. pp. 544, Elsevier, Amsterdam.

Williams, Q. (1995) Infrared, Raman and optical spectroscopy of Earth Materials. In Mineral Physics and Crystallography : A Handbook of Physical Constants (Ahrens, T.J. Ed.). pp. 354, American Geophysical Union, Washington, D.C., 291-301.

Manuscript received May 14, 2008

Manuscript accepted September 29, 2008

Manuscript handled by Masaki Enami 